\title{
Gestão de custos de matérias-primas em indústrias de conserva de pescado do Brasil e da Espanha
}

\begin{abstract}
Rodrigo dos Santos Cardoso
Mestrado em andamento em Ciências Contábeis pela Universidade Regional de

Blumenau - FURB

Rua Antonio Veiga, 104 (FURB/PPGCC). Blumenau/SC. CEP: 89012-900

E-mail:rodrigocardososc@yahoo.com.br

Ilse Maria Beuren

Doutorado em Controladoria e Contabilidade pela Universidade de São Paulo - USP

Professora da Universidade Regional de Blumenau - FURB

Rua Antonio Veiga, 104 (FURB/PPGCC). Blumenau/SC. CEP: 89012-900

E-mail: ilse@furb.br
\end{abstract}

\section{RESUMO}

O objetivo deste estudo é analisar comparativamente a forma da gestão dos custos de matérias-primas em indústrias de conserva de pescado do Brasil e da Espanha, face à escassez de pescado no mundo. O método da pesquisa é descritivo, do tipo levantamento, com abordagem predominantemente qualitativa. A população da pesquisa compreende as indústrias de conserva de pescado do Brasil e da Espanha. A amostra não probabilística, do tipo intencional, se compõe, no Brasil, das três maiores empresas do mercado de conserva de pescado, listadas na Gazeta Mercantil; e na Espanha, de duas empresas de conserva de pescado listadas na Associação Nacional dos Fabricantes de Conserva de Pescado e Marisco. Conclui-se que a forma da gestão dos custos de matérias-primas em indústrias de conserva de pescado do Brasil e da Espanha apresenta semelhanças em alguns aspectos e difere em outros.

Palavras-chave: Gestão de custos. Matérias-primas. Pescado. Escassez. Indústrias de conserva de pescado.

\section{Costs management of raw materials in the fisch industries of Brazil and Spain}

\section{ABSTRACT}

The objective of this study is to make a comparative analysis of the management of raw material costs in the fish industries of Brazil and Spain, in the face of the growing scarcity of fish in the world. The research methodology is descriptive, of a survey type with a predominantly qualitative approach. The research population comprises the fish industries of Brazil and Spain. The sample was a non-probabilistic intentional type, made up of the three major fish companies in Brazil, as listed in the Gazeta Mercantil; and the two major equivalents in Spain, as listed in the Associação Nacional dos 
Gestão de custos de matérias-primas em indústrias de conserva de pescado do Brasil e da

Espanha

Rodrigo dos Santos Cardoso, Ilse Maria Beuren

Fabricantes de Conserva de Pescado e Marisco. It was concluded that the management systems for raw material costs in fish industries in Brazil and in Spain have similarities in some aspects and differences in others.

Key Words: Cost management. Raw materials. Fish. Scarcity. Fish industries.

\section{INTRODUÇÃO}

A gestão de custos nas empresas nasceu da necessidade de não apenas controlar as empresas e sim influenciar nos aspectos decisórios dos gestores. As informações de custos são relevantes para que os administradores possam verificar a viabilidade ou não de produtos, atividades, divisões ou de negócios de uma organização.

A gestão de custos implica coleta de dados, acumulação dos dados (organização das informações, interpretação e análise) e as informações propriamente ditas (relatórios gerenciais). Esta cadeia precisa ser alimentada de forma organizada e inteligível aos gestores, que são os usuários finais dessas informações, pois assim os relatórios gerados poderão ser úteis à gestão dos custos.

Os gestores não apenas necessitam de controles, que são inerentes a este tipo de informação gerada, mas precisam de informações com visão holística do negócio, capaz de subsidiar rápidas mudanças no rumo dos negócios. Hansen e Mowen (2001, p. 28) mencionam que a "gestão de custos produz informações para os usuários internos [...] identifica, coleta, mensura, classifica e relata informações que são úteis aos gestores para o custeio (determinar quanto algo custa), planejamento, controle e tomada de decisão".

Para mensurar os custos dos produtos nos processos industriais, consideram-se os elementos de custos: materiais consumidos para o produto e o processo industrial, mão-de-obra industrial e gastos gerais de fabricação, incluindo depreciação das instalações e equipamentos industriais. Os materiais consumidos nos produtos e que sofrem transformação ao longo do processo consubstanciam-se em matérias-primas.

As matérias-primas configuram o ponto inicial de todo o processo industrial, visto que no planejamento ou alocação de uma unidade de fabricação, esta precisa estar 
disponível de forma adequada e a custos competitivos.

A matéria-prima pescado, base para indústrias de conserva de pescado, passa por dificuldades de abastecimento. Muitas vezes precisa ser controlada em seus estoques, devido à escassez premente em diversos locais. Sua captura desenfreada também força governos a estabelecerem cotas de pesca ou períodos de captura, para que este ramo de atividade ainda sobreviva de forma sustentável.

A sustentabilidade das empresas no Brasil, conforme Everest Filho e Siqueira (1997, p.2), denota que "os motivos para o declínio das empresas de conserva de pescado no Brasil foram vários. Dentre os principais destaca-se a escassez de matériaprima, devido à pesca predatória da espécie de sardinha". As empresas que diversificaram suas produções e passaram a fazer também conservas de pescado da espécie atum conseguiram se manter no mercado.

Por outro lado, segundo o portal da União Européia (EUROPA, 2005), a Espanha configura-se, atualmente, dentre os países participantes da União Européia com maior número de empresas de transformação de pesca, que engloba as empresas de conserva de pescado. O pescado constitui-se em preocupação constante para as empresas de conserva de pescado, devido à necessidade de importação da matériaprima, escassez e sazonalidade de suprimentos, além de acordos internacionais de captura.

Assim, este estudo tem como objetivo analisar comparativamente a forma da gestão dos custos de matérias-primas em indústrias de conserva de pescado do Brasil e da Espanha, em face da escassez de pescado no mundo. O estudo mostra-se relevante por ampliar os conhecimentos teóricos sobre o tema e fundamentar 0 processo decisório com vistas à sustentabilidade, em face do ambiente de escassez de matéria-prima.

O artigo inicia com esta introdução, na seqüência abordam-se fundamentos teóricos sobre gestão de custos e gestão de custos em conservas de pescado. Após, evidenciam-se a metodologia da pesquisa, os resultados da pesquisa e as considerações finais do estudo. 
Gestão de custos de matérias-primas em indústrias de conserva de pescado do Brasil e da

Espanha

Rodrigo dos Santos Cardoso, Ilse Maria Beuren

\section{COMPONENTES DA GESTÃO DE CUSTOS}

As matérias-primas compreendem o elemento que inicia 0 processo de transformação industrial. Os custos das matérias-primas são, de maneira geral, controlados de modo a assegurar a continuidade dos processos de manufatura, de forma a viabilizar economicamente os negócios das empresas. Portanto, as matériasprimas são elementos relevantes na gestão de custos, especialmente nas organizações que as utilizam em grandes proporções.

A gestão de custos das matérias-primas leva em consideração uma série de necessidades ou imposições de suprimentos, especificados por Francischini e Gurgel (2002, p.40) por "demanda, política de reposição, lote de compra, tempo de espera para entrega dos pedidos, restrições impostas pela alta administração, hábitos e costumes dos consumidores, sazonalidade, moda, obsolescência técnica, estações do ano, épocas do ano, preço e importância relativa".

Ainda que existam diferenças significativas em cada ramo de atividade, esses fatores, de maneira geral, são comuns em maior ou menor intensidade em qualquer empresa. Nota-se, portanto, que a gestão de custos das matérias-primas deve moldarse às imposições do mercado, dos consumidores e fornecedores, ou até mesmo de imposições e políticas da alta administração das empresas.

As necessidades ou imposições de suprimentos precisam ser gerenciadas à luz do resultado econômico das empresas, e podem ser melhor gerenciadas por meio de sistemas. Hansen e Mowen (2001, p. 55) definem sistema como "um conjunto de partes inter-relacionadas que realiza um ou mais processos para atingir objetivos específicos". Destacam os sistemas de projeto e desenvolvimento, sistemas de produção, sistemas de marketing e distribuição e sistemas de serviços ao cliente.

Para este estudo interessam especificamente os sistemas de gestão de custos. O termo sistema de custos, conforme Leone (2000, p. 234), é "empregado para definir o conjunto de componentes administrativos, de registros, de fluxos, de procedimentos e de critérios que agem e interagem de modo coordenado objetivo, que, no caso é o custeio da produção e do produto". Os sistemas de custos precisam ser alimentados 
Gestão de custos de matérias-primas em indústrias de conserva de pescado do Brasil e da Espanha

Rodrigo dos Santos Cardoso, Ilse Maria Beuren

por outros sistemas existentes nas organizações, demonstrando assim integração e interação com o todo. O sistema de gestão de custos necessita ter perspectiva organizacional, que permeie todos os sistemas da organização, permitindo que as demais áreas tenham a gestão de custo como foco de suas ações.

Consubstanciado pelas necessidades de sistemas de custos, a contabilidade de custos utiliza, para fornecer informações às diversas necessidades gerenciais, diferentes sistemas de acumulação de custos. A escolha do sistema mais adequado depende exclusivamente das características da empresa, tanto em termos de tipo de produção, tecnologia ou produto a ser fabricado. Como sistemas de acumulação de custos têm-se os sistemas de acumulação por ordem de produção ou por processo.

O sistema de acumulação por ordem de produção é característico de empresas que fabricam lotes únicos ou produtos individuais. Exemplos deste tipo de empresa são: construtoras; fabricantes de equipamentos específicos e sob encomendas de outras empresas; gráficas. Jiambalvo (2002, p. 23-24) ressalta que "uma ordem de produção é um produto individual, ou lote para o qual a empresa precisa de informações de custo".

A acumulação de custos por processo é freqüentemente utilizada por empresas que possuem poucas matérias-primas e, conseqüentemente, poucos produtos manufaturados, em termos de diversidade, e feitos de forma padronizada em um mesmo processo de fabricação. Horngren, Foster e Datar (2000, p. 434) reforçam esta característica, salientando que "nessas indústrias, produtos relativamente homogêneos são processados de modo muito parecido e, assim, supõe-se que recebam a mesma quantidade de materiais diretos e mão-de-obra direta e de custos de fabricação indiretos".

No sistema de acumulação de custos, têm-se diferentes métodos de custeio, que dão suporte à gestão de custos. Por meio dos métodos de custeio "se mensuram e relatam informações financeiras e não financeiras relacionadas à aquisição e ao consumo de recursos pela organização" (HORNGREN; FOSTER; DATAR, 2000, p. 2). Consubstancia-se nesta assertiva o significado de custeio, que para Martins (2000, p. 41) "é método de apropriação de custo". Dentre estes métodos destacam-se o custeio por absorção, o custeio direto ou variável e o custeio baseado em atividades (ABC). 
Custeio por absorção, de acordo com Leone (2000, p. 242), "é aquele que faz debitar ao custo dos produtos todos os custos da área de fabricação, sejam esses definidos como custos diretos ou indiretos, fixos ou variáveis, de estrutura ou operação". Desta forma, para cada produto recai uma parcela de custos, tanto diretos e indiretos, como fixos e variáveis, quando este é fabricado. Este método de custeio é "aderente aos princípios fundamentais de contabilidade utilizados praticamente em todo mundo, tanto na legislação comercial quanto pela legislação fiscal" (PADOVEZE, 2003, p. 79).

No custeio variável, conforme Maher (2001, p. 360), "apenas os custos variáveis de produção são atribuídos às unidades produzidas; os custos fixos de produção são considerados despesas do período". Como condições, Leone (2000, p. 391-392) salienta que é necessário: a) que ele tenha relação direta com o objeto de custeio; e b) que ele seja variável em relação a operação que está sendo custeada.

Como implica separação dos custos em fixos e variáveis, este método permite uma análise dos gastos e receitas das empresas, com relação aos volumes produzidos ou vendidos. Desta forma, é demonstrada por este método de custeio a margem de contribuição. Para Leone (2000, p. 40-41), "a margem de contribuição é a diferença entre o preço de venda unitário e o custo de venda variável unitário".

A utilização deste método fornece também o ponto de equilíbrio da empresa. $O$ ponto de equilíbrio é utilizado quando se pode avaliar o risco operacional, além de algumas restrições de linearidade dos custos, comportamentos confiáveis em um período de trabalho, assim como a separação dos custos fixos e variáveis com comportamentos previsíveis quando do aumento ou baixa de volume de produção (SANTOS, 2005).

O método de custeio baseado em atividades (Activity-Based Costing - $A B C$ ), segundo Kaplan e Cooper (1998), fornece um conjunto de respostas para as seguintes perguntas anteriormente não respondidas pelos métodos tradicionais: Que atividades estão sendo executadas? Quanto custa executar estas atividades? Por que a organização precisa executar estas atividades? Quanto de cada atividade é demandado objetos de custeio?

Hansen e Mowen (2001, p. 392) explicam que este sistema "primeiramente 
Gestão de custos de matérias-primas em indústrias de conserva de pescado do Brasil e da Espanha

Rodrigo dos Santos Cardoso, Ilse Maria Beuren

rastreia os custos para as atividades e, em seguida, para os produtos e outros objetos de custo. A suposição subjacente é que as atividades consomem recursos, e os produtos e outros objetos de custo consomem atividades". Portanto, primeiramente identificam-se as atividades, pois são estas que consomem os recursos. A soma dos recursos empreendidos nas atividades é que são alocados aos produtos, utilizando os direcionadores para alocá-los.

Basicamente a diferença entre o custeio baseado por atividade e os métodos tradicionais está centrada na alocação mais adequada dos custos indiretos de produção quando se está aplicando o custeio baseado em atividades. Os custos indiretos não variam de acordo com o volume de produção em determinadas linhas de manufaturas e são pressupostamente diretamente proporcionais, quando se está analisando por intermédio dos custeios tradicionais.

As matérias-primas não são afetadas em termos de custos pela utilização de um ou outro método de custeio. Tal decorre do fato desse elemento de custos ser tratado de forma igual em qualquer método de custeio, seja ele por absorção, variável ou baseado em atividades. As principais distorções de custos decorrem de custos indiretos incidentes sobre produtos de alta quantidade de produção e de baixa quantidade, dependendo da atividade, por exemplo, setup de máquina. Assim, o produto de alta produção pode estar sendo supervalorizado em detrimento aos produtos de baixa quantidade de produção.

\section{CUSTOS DAS MATÉRIAS-PRIMAS NA CONSERVA DE PESCADO}

Semelhante a outros processos industriais, no ramo de conserva de pescado a gestão de custos responde à indagações que a maioria das empresas fazem, como: "A empresa deve adicionar um novo produto? Deve abandonar um produto existente? Deve fabricar um componente usado na montagem do seu principal produto ou contratar uma empresa para produzi-lo? Qual preço a empresa deve cobrar por um novo produto?" (JIAMBALVO, 2002, p. 3). Depreende-se que a gestão de custos implica dar suporte às empresas através de sistemas de informações, sobre sua 
Gestão de custos de matérias-primas em indústrias de conserva de pescado do Brasil e da

Espanha

Rodrigo dos Santos Cardoso, Ilse Maria Beuren

rentabilidade futura e, possivelmente, à sua sobrevivência.

A conserva de pescado, em seu processo de fabricação, possui um sistema contínuo de fabricação. Esta particularidade fornece de maneira substancial fatores geradores de estoque que, por conseqüência, agregam custo ao produto, e à matériaprima pescado em específico. Viana (2000) identifica causas que exigem estoque permanente de matérias-primas: a) continuidade operacional; b) incerteza da demanda futura; e c) disponibilidade imediata do material nos fornecedores.

A incerteza da disponibilidade da matéria-prima confere ao ramo de conserva de pescado, no que concerne à matéria-prima pescado, custos adicionais, tais como, manutenção de estoques reguladores, armazenagem, logística de abastecimento e movimentação de mercadoria, taxas de importação e frete, entre outros. A gestão de custos de matérias-primas na conserva de pescado precisa considerar as particularidades deste ramo, e as interferências destes nas decisões da organização, principalmente em um ambiente de escassez de pescado.

Segundo Francischini e Gurgel (2002, p.82), "com freqüência, a empresa não consegue responder rapidamente a aumentos bruscos da demanda, havendo necessidade de estoques de produtos acabados para atender estes aumentos; em outras ocasiões, a entrega de matéria-prima não acompanha as necessidades de produção". Desta forma, as empresas justificam a formação de estoques, elevando seus custos operacionais e financeiros, podendo comprometer seus resultados.

Empresas de conserva de pescado precisam estar nos potenciais mercados fornecedores de matéria-prima, ou possuir uma logística de importação regular para suprir suas necessidades. Do contrário, serão forçadas a armazenar grandes volumes de pescado e os rateios dos gastos com armazenagem podem incidir indiretamente nos produtos ao invés de serem acrescidos à matéria-prima. Martins (2000, p. 125) adverte que, "quando há oscilações nos volumes de produção ou nos custos de armazenagem, pode ocorrer o fato indesejado de se estar jogando custos de estocagem de material a ser usado no período seguinte como custo do produto elaborado no mês anterior".

O valor pago ao fornecedor pela matéria-prima pescado, pode ter agregado outros custos. Para Gurgel (2002, p. 187), "no valor pago pela compra de um material 
deve-se incluir as despesas de transporte, armazenagem, importação e outros custos de aquisição". Salienta-se neste caso específico, do ramo de conserva de pescado, a inclusão dos custos de armazenagens e importações, especificamente quando se trata de falta de suprimentos e suas perspectivas de escassez.

De acordo com Francischini e Gurgel (2002), a gestão dos estoques de matériasprimas deverá conciliar vários interesses, de diferentes departamentos, em uma mesma empresa (compras, produção, vendas e financeiro). Sendo assim, interfere na operacionalidade da empresa caso esta gestão não seja conciliadora e eficaz.

Diversas fontes de informação disparam a necessidade de compra das matériasprimas. Slack et al. (1997) salientam que se inicia pelo programa mestre de produção. O programa mestre de produção é alimentado pela carteira de pedidos da empresa e pela previsão de venda. No caso específico do ramo de conserva de pescado, agregam-se outros fatores, como o histórico de utilização em cada época do ano já definido por sazonalidade da demanda e a oportunidade de oferta durante o ano da matéria-prima pescado.

Por se tratar de um produto perecível, o pescado possui um tratamento diferenciado em sua movimentação, precisa sempre se manter a temperaturas rigidamente definidas para que esteja em condições adequadas de uso. Esta ressalva em sua utilização concede ao pescado um fluxo de movimentação, dentro do processo produtivo, contínuo e de rápida manipulação, assim como de tempos de armazenagens curtos.

A gestão de matéria-prima pescado requer dinâmica na tomada de decisão. As incertezas das demandas favorecem riscos de custos adicionais de estoques para evitar um custo maior que seria a falta de matéria-prima no momento que se faz necessária a produção. Viana (2000) identifica estes fatores como influências externas e dentre estas influências destacam-se, a segurança contra riscos de produção, cumprimento de prazos de entrega (distância dos fornecedores), disponibilidade de mercado (fornecedor exclusivo, escassez).

Acrescenta-se ao exposto que a gestão de matérias-primas na indústria de conserva de pescado convive com o fator de escassez de determinadas espécies e se 
Gestão de custos de matérias-primas em indústrias de conserva de pescado do Brasil e da

Espanha

Rodrigo dos Santos Cardoso, Ilse Maria Beuren

contrapõem aos dados mundiais de expansão de consumo de pescado no mundo, conforme Gazeta Mercantil (2003). Há um mercado em franca expansão de consumo aliado a sistemas de proteção e controle de pesca para garantir a sustentabilidade de determinadas espécies de pescado.

A gestão de custos de matérias-primas na conserva de pescado precisa considerar as particularidades deste ramo, além das interferências destes nas decisões da organização, principalmente em um ambiente de escassez de pescado. A necessidade de ter os materiais nos tempos certos, nas quantidades necessárias, no exato momento de fabricação, a custos competitivos, são as diretrizes de uma administração eficiente de materiais.

\section{METODOLOGIA DA PESQUISA}

Esta pesquisa caracteriza-se por ser do tipo descritiva. Segundo Oliveira (1997, p. 114), a pesquisa descritiva "possibilita o desenvolvimento de um nível de análise em que se permite identificar as diferentes formas dos fenômenos, sua ordenação e classificação".

A pesquisa descritiva teve como base um levantamento ou survey. De acordo com Gil (1999, p. 70), o levantamento é a "interrogação direta das pessoas, cujo comportamento se deseja conhecer. Solicita-se informações a um grupo significativo de pessoas acerca do problema estudado para, em seguida, mediante análise quantitativa, obter as conclusões correspondentes dos dados coletados".

As empresas selecionadas no Brasil compreendem as principais indústrias de conserva de pescado listadas pela Gazeta Mercantil, em 2003, considerando o faturamento: Pepsico do Brasil Ltda. (marca Coqueiro), a GDC Alimentos S.A. (marca Gomes da Costa) e a Femepe Indústria e Comércio de Pescados S.A. (marca Pescador). Estas três empresas representam $98 \%$ do faturamento total em conservas de pescado no Brasil.

$\mathrm{Na}$ Espanha, consideraram-se as maiores empresas listadas na Associação Nacional dos Fabricantes de Conserva de Pescado e Marisco (ANFACO), que totaliza 
Gestão de custos de matérias-primas em indústrias de conserva de pescado do Brasil e da

Espanha

Rodrigo dos Santos Cardoso, Ilse Maria Beuren

147 empresas de conserva de pescado (ANFACO, 2005). As empresas escolhidas foram as que tiveram maior faturamento no ano de 2005 (ANFACO, 2005). Os contatos com as empresas deram-se através dos endereços eletrônicos contidos no sítio da ANFACO, no qual também se obteve, na maioria dos casos, os nomes dos responsáveis das áreas pesquisadas.

Portanto, a amostra caracteriza-se como intencional e não probabilística. Oliveira (1997, p.161) define a amostragem não probabilística como "aquela que inclui em uma pesquisa uma variedade bastante grande de técnicas, possibilitando ao pesquisador a escolha de um determinado elemento do universo".

Embora o instrumento de pesquisa tenha sido enviado para as 31 maiores empresas listadas na ANFACO, somente duas responderam as questões. Desse modo, constitui-se uma amostra por acessibilidade, ou seja, na qual o pesquisador seleciona os sujeitos a que tem acesso, admitindo que possam representar o universo de análise.

As áreas focalizadas nas empresas de conserva de pescado, tanto no Brasil como na Espanha, foram: controladoria, suprimentos e marketing. Estas áreas foram selecionadas porque estão ligadas diretamente às implicações com a matéria-prima, que é o objeto de estudo. A área de suprimentos acredita-se ser a responsável pelo abastecimento. A área de controladoria pelos controles e a visão holística da empresa. A área de marketing responsável pelo posicionamento da empresa no mercado frente a problemas com a matéria-prima.

A coleta de dados ocorreu em julho e agosto de 2006, por meio de um questionário estruturado com perguntas fechadas e abertas. Para Cervo e Bervian (1996, p. 138), o questionário "é a forma mais usada para coletar dados, pois possibilita medir com melhor exatidão o que se deseja". Elaboraram-se três questionários, um para cada área focalizada da empresa de conserva de pescado.

$\mathrm{Na}$ análise dos dados considerou-se o objetivo estabelecido, que é uma comparação entre estes dois países, Brasil e Espanha, em relação à gestão de custos das matérias-primas nas indústrias de conserva de pescado. A análise deu-se à luz dos conceitos abordados na revisão da literatura acerca desta temática.

Utilizou-se predominantemente a abordagem qualitativa na análise dos dados. $\mathrm{O}$ 
Gestão de custos de matérias-primas em indústrias de conserva de pescado do Brasil e da

Espanha

Rodrigo dos Santos Cardoso, Ilse Maria Beuren

método quantitativo caracteriza-se pelo emprego de instrumental estatístico como base no processo de análise de um problema (RICHARDSON et al, 1999). Por sua vez, na pesquisa qualitativa "estabelecem-se qualidades a serem medidas. São consideradas as questões de pesquisa" (BOENTE; BRAGA, 2004, p. 12).

A pesquisa realizada apresenta algumas limitações, sendo que basicamente todas decorrem da estratégia definida para a coleta dos dados. Uma delas deve-se ao fato do questionário ter sido enviado sem saber como ocorre a gestão de custos de matérias-primas nestas empresas. Outra decorre da forma da aplicação do questionário nas empresas, que limitou a possibilidade de exploração das respostas, o que seria possível no caso de entrevistas com os respondentes. A terceira relaciona-se com a pequena quantidade de questionários respondidos pelas empresas espanholas.

\section{GESTÃO DE CUSTOS DE MATÉRIAS-PRIMAS NAS EMPRESAS DE CONSERVA DE PESCADO DO BRASIL E DA ESPANHA}

Para avaliar como as empresas de conserva de pescado do Brasil e da Espanha estruturam a gestão de custos da matéria-prima pescado, formularam-se questionamentos acerca de sistemas de custos, métodos de custeio, instrumentos/variáveis de gestão de custos empregados nestas empresas, além dos controles e formas de gerenciamento que as mesmas empregam em seu processo de produção.

Os resultados destes questionamentos proporcionaram analisar comparativamente a forma de gestão de custos de matérias-primas nas empresas de conserva do Brasil e da Espanha. Uma síntese das respostas a estes questionamentos é evidenciada no Quadro 1. 
Gestão de custos de matérias-primas em indústrias de conserva de pescado do Brasil e da
Espanha

Rodrigo dos Santos Cardoso, llse Maria Beuren

\begin{tabular}{|c|c|c|}
\hline $\begin{array}{c}\text { Aspectos da gestão de custos } \\
\text { de matérias-primas }\end{array}$ & Brasil & Espanha \\
\hline $\begin{array}{l}\text { Responsabilidade da compra da } \\
\text { matéria-prima pescado }\end{array}$ & $\begin{array}{c}\text { Há um setor específico para } \\
\text { compra da matéria-prima } \\
\text { subordinado ao alto escalão } \\
\text { das empresas } \\
\end{array}$ & $\begin{array}{c}\text { Há um setor específico para } \\
\text { compra da matéria-prima } \\
\text { subordinado ao alto escalão das } \\
\text { empresas }\end{array}$ \\
\hline $\begin{array}{l}\text { Grau de importância dado à } \\
\text { matéria-prima pescado }\end{array}$ & Elevado & Elevado \\
\hline Origem da matéria-prima pescado & $70 \%$ importada & $30 \%$ importada \\
\hline Uso da matéria-prima & $60 \%$ conserva de sardinha & $69 \%$ conserva de atum \\
\hline $\begin{array}{l}\text { Controle e programação de } \\
\text { matéria-prima pescado }\end{array}$ & $\begin{array}{c}\text { Maioria usa sistema ERP, } \\
\text { somente uma empresa do } \\
\text { Brasil não utiliza sistema } \\
\text { informatizado. }\end{array}$ & $\begin{array}{l}\text { Há sistema informatizado para } \\
\text { esta finalidade }\end{array}$ \\
\hline $\begin{array}{l}\text { Disparo da necessidade de } \\
\text { compra da matéria-prima }\end{array}$ & Previsão de venda & Previsão de venda \\
\hline $\begin{array}{l}\text { Cálculo para compra da matéria- } \\
\text { prima }\end{array}$ & $\begin{array}{l}\text { Somente uma empresa utiliza } \\
\text { o software de gestão, as } \\
\text { demais utilizam o Lote } \\
\text { Econômico de Compra (LEC) }\end{array}$ & Não utiliza cálculo \\
\hline Método de avaliação dos estoques & Custo médio & $\begin{array}{l}\text { A maior empresa utiliza custo } \\
\text { médio, a menor por lote }\end{array}$ \\
\hline $\begin{array}{l}\text { Armazenagem e tempo de reserva } \\
\text { médio de estoque }\end{array}$ & 30 a 90 dias & 90 a 180 dias \\
\hline $\begin{array}{l}\text { Percentual médio do elemento de } \\
\text { custo matéria-prima pescado, no } \\
\text { custo final do produto }\end{array}$ & $49,3 \%$ & $52 \%$ \\
\hline $\begin{array}{l}\text { Relatório de acompanhamento da } \\
\text { variação de custo da matéria-prima }\end{array}$ & $\begin{array}{l}\text { Uma empresa mensal. Outra } \\
\text { empresa diário e por } \\
\text { indicadores de performance. A } \\
\text { terceira possui três relatórios: } \\
\text { diário, mensal e por } \\
\text { indicadores de performance }\end{array}$ & $\begin{array}{l}\text { Mensal, após fechamento } \\
\text { contábil }\end{array}$ \\
\hline Sistema de acumulação de custos & Por ordem ou por lote & Por ordem ou por lote \\
\hline Métodos de custeio & Variável ou direto & Absorção \\
\hline Necessidades para sobrevivência & $\begin{array}{l}\text { Investir em tecnologia e } \\
\text { controle de custos }\end{array}$ & $\begin{array}{l}\text { Estar presente em regiões } \\
\text { produtoras de pescado e investir } \\
\text { em maior valor agregado aos } \\
\text { produtos da conserva de } \\
\text { pescado }\end{array}$ \\
\hline $\begin{array}{c}\text { Integração das áreas com a } \\
\text { compra de pescado }\end{array}$ & Fraco a médio & Médio \\
\hline $\begin{array}{c}\text { Análise de ameaças ambientais e } \\
\text { oportunidades }\end{array}$ & Fraca/Média & Médio \\
\hline $\begin{array}{l}\text { Tendência dos produtos de } \\
\text { conserva de pescado }\end{array}$ & Gerar valor agregado & Gerar valor agregado \\
\hline Influência sobre o preço de venda & $\begin{array}{l}\text { Custo de produção e mercado } \\
\text { consumidor }\end{array}$ & $\begin{array}{l}\text { Custo de produção e mercado } \\
\text { consumidor }\end{array}$ \\
\hline
\end{tabular}

Quadro 1: Análise comparativa da gestão de custos de matérias-primas em empresas brasileiras e espanholas

Fonte: dados da pesquisa. 
Gestão de custos de matérias-primas em indústrias de conserva de pescado do Brasil e da Espanha

Rodrigo dos Santos Cardoso, Ilse Maria Beuren

A análise do Quadro 1 indica que a gestão da matéria-prima pescado possui um tratamento diferenciado nas empresas pesquisadas. Em todas as empresas pesquisadas existem departamentos específicos para compra do pescado e estes respondem diretamente para os altos escalões de executivos das empresas. Esta distinção denota a importância dada à esta matéria-prima, considerada estratégica pelas empresas de conserva de pescado pesquisadas.

A matéria-prima principal das empresas de conserva de pescado do Brasil, a sardinha, provém do mercado internacional. Devido ao não suprimento de pesca nacional desta espécie e a sobrepesca, as empresas brasileiras recorrem à importação para suprir suas necessidades de produção, sendo que cerca de $70 \%$ da matéria-prima é adquirida de fora do País. Por conseguinte, há um significativo aumento dos custos da matéria-prima, visto que os custos de importação são acrescidos ao custo do pescado.

Para o controle e programação de matérias-primas, nas empresas brasileiras somente uma não utiliza procedimento informatizado para compra e programação de necessidades da matéria-prima, as demais utilizam sistemas ERP para esta finalidade. Nas empresas analisadas da Espanha, estas utilizam softwares para controle e programação de compra da matéria-prima.

O disparo de compra e necessidade da matéria-prima pescado, nas empresas brasileiras e espanholas pesquisadas, é iniciado principalmente pela previsão de venda, pois a quantidade a ser utilizada para cada produto a ser fabricada é fixa e calculada previamente. O método de avaliação dos estoques adotado é o custo médio. Somente na empresa de menor porte da Espanha o método de avaliação de estoque verificado é por lote.

No Brasil, a armazenagem e reserva média de estoque da matéria-prima, devido a pericibilidade do pescado, assim como os custos de armazenagem, fazem com que as empresas possuam, apesar de importarem 70\% da matéria-prima, somente 30 a 90 dias de estoques. Esta realidade também é confirmada na maior empresa da Espanha pesquisada.

O elemento de custo de maior percentual, em relação ao custo total da conserva 
Gestão de custos de matérias-primas em indústrias de conserva de pescado do Brasil e da

Espanha

Rodrigo dos Santos Cardoso, Ilse Maria Beuren

de pescado, é a matéria-prima pescado, $45 \%$ em média. Isto confirma a importância estratégica da gestão de custos da matéria-prima pescado. Apesar da importância estratégica, duas das empresas brasileiras utilizam relatórios mensais de acompanhamento da evolução de custos, após fechamento contábil, demonstrando assim, uma possível fragilidade em prever cenários de mudanças bruscas no ambiente desta matéria-prima. O que se confirma quando analisado o baixo grau de desempenho da controladoria na presente pesquisa.

O sistema de acumulação de custos utilizado nas empresas de conserva de pescado é somente por ordem de produção ou lote, devido ser um material altamente perecível em todo seu processo de manufatura.

Os métodos de custeio aplicados para análise gerencial nas empresas de conserva de pescado do Brasil, é o custeio variável ou direto. A empresa da Espanha analisada utiliza o método de custeio por absorção. Com a utilização do custeio variável indentifica-se a margem de contribuição individual por produto, além da margem global da empresa. Neste método dispensa-se o rateio dos custos fixos, que são deduzidos diretamente do resultado do período. Infere-se que a empresa da Espanha, por possuir várias unidades em diferentes países, opte por utilizar o custeio por absorção para que tenha uma visão uniforme dos custos nas diferentes unidades de produção.

\section{CONSIDERAÇÕES FINAIS}

O estudo teve como objetivo analisar comparativamente a forma da gestão dos custos de matérias-primas em indústrias de conserva de pescado do Brasil e da Espanha, face à escassez de pescado no mundo. O método da pesquisa adotado é descritivo, do tipo levantamento, com abordagem predominantemente qualitativa. A amostra da pesquisa se compôs, no Brasil, das três maiores empresas do mercado de conserva de pescado, listadas na Gazeta Mercantil; e na Espanha, de duas empresas de conserva de pescado listadas na Associação Nacional dos Fabricantes de Conserva de Pescado e Marisco.

O futuro do ramo da conserva de pescado no Brasil é bastante preocupante, 
devido à carência e necessidades apontadas de investimentos em tecnologia de fabricação e controle de custos, aliadas à falta de suprimentos da principal matériaprima pescado e à evolução de queda acentuada de sobrevivência das empresas nos últimos anos. Na Espanha, denota-se que há desenvolvimento maior em tecnologia, inserção em mercados globalizados, diversificação de produtos e com maior valor agregado, preocupação com abastecimento a partir da busca de grandes regiões produtoras de pescado.

A gestão de custos das matérias-primas apresenta-se dificultosa sob diversos aspectos verificados na pesquisa, especialmente devido a falta de integração das áreas das empresas, tanto no Brasil como na Espanha, particularmente com a área de compra de pescado, responsável pela compra da matéria-prima. Esta falta de integração dificulta o fluxo de informações advindas de outros sistemas existentes nas empresas e que necessitam estar integradas ao sistema de gestão de custos, para que este cumpra sua finalidade de fornecer subsídios às tomadas de decisões.

O preço de venda da conserva de pescado é fortemente influenciado pelo custo de produção e pelo mercado consumidor, tanto no Brasil como na Espanha. O primeiro é impactado diretamente com o peso do custo da matéria-prima pescado no custo final do produto. O segundo se refere às outras fontes alternativas de suprimentos de proteínas atualmente existentes na alimentação humana.

Assim, conclui-se que pela análise comparativa da forma de gestão dos custos de matérias-primas em indústrias de conserva de pescado do Brasil e da Espanha, que há semelhanças em alguns aspectos entre as empresas dos dois países, mas também há divergências na conduta face à escassez de pescado no mundo.

Face às limitações desta pesquisa, recomenda-se para estudos futuros ampliar a pesquisa na Espanha, aplicando o mesmo instrumento de pesquisa nas maiores empresas da Espanha e comparar com as maiores do Brasil; investigar a forma de gestão dos custos de matérias-primas em indústrias de conserva de pescado de outros países que fabricam conserva de pescado e comparar com os resultados desta pesquisa. 
Gestão de custos de matérias-primas em indústrias de conserva de pescado do Brasil e da

Espanha

Rodrigo dos Santos Cardoso, llse Maria Beuren

\section{REFERÊNCIAS}

ANFACO - Asociación Nacional de Fabricantes de Conservas de Pescados y Mariscos. (2006). Presentación de los datos correspondientes al año 2005 del sector industrial transformador de productos del mar. Disponível em: <www.anfaco.es. Acesso em: $15 /$ jun.

BOENTE, Alfredo; BRAGA, Gláucia. (2004). Metodologia científica contemporânea para universitários e pesquisadores. Rio de Janeiro: Brasport. 175 p.

CERVO, Amado Luiz; BERVIAN, Pedro Alcino. (1996). Metodologia científica. (4 ed.). São Paulo: Makron Books.

EUROPA (2005). Portal da União Européia. A atividade da União Européia por tema: pesca. Disponível em: http://europa.eu.int/comm/fisheries/doc_et_publ/list_publi/ transformation 05_fr.pdf. Acesso em: 21/mar/2006.

EVEREST FILHO, Paulo; SIQUEIRA, Sandra Helena G. (1997). Panorama da pesca marítima no mundo e no Brasil. Disponível em: <www.bndes.gov.br/conhecimento/bnset/rspesca.pdf>. Acesso em: 11/nov/2004.

FRANCISCHINI, Paulino G.; GURGEL, Floriano do Amaral. (2002). Administração de materiais e do patrimônio. São Paulo: Pioneira Thomson.

GAZETA MERCANTIL. (2003). Panorama setorial: a indústria do pescado. São Paulo: Gazeta Mercantil. 146 p.

GIL, Antonio Carlos. (1999). Métodos e técnicas de pesquisa social. (5 ed.). São Paulo: Atlas.

HANSEN, Don R.; MOWEN, Maryanne M. (2001). Gestão de custos e contabilidade e controle. São Paulo: Pioneira.

HORNGREN, Charles T.; FOSTER, George; DATAR, Srikant M. (2000). Contabilidade de Custos. 9.ed. Rio de Janeiro: LTC.

JIAMBALVO, James. (2002). Contabilidade gerencial. Rio de Janeiro: LTC, 2002. 280p.

KAPLAN, Robert S.; COOPER, Robin. (1998). Custo e desempenho: administre seus custos para ser mais competitivo. São Paulo: Futura. 376 p.

LEONE, George Sebastião Guerra. (2000). Custos: planejamento, implantação e controle. 3.ed. São Paulo: Atlas. 518 p. 
Gestão de custos de matérias-primas em indústrias de conserva de pescado do Brasil e da

Espanha

Rodrigo dos Santos Cardoso, Ilse Maria Beuren

MAHER, Michael. (2001). Contabilidade de custos: criando valor para a administração. São Paulo: Atlas. 905 p.

MARTINS, Eliseu. (2000). Contabilidade de custos. (7 ed.). São Paulo: Atlas. 388 p.

OLIVEIRA, Silvio Luiz de. (1997). Tratado de metodologia científica: projetos de pesquisas, TGI, TCC, monografias, dissertações e teses. São Paulo: Pioneira. 320 p.

PADOVEZE, Clóvis Luíz. (2003). Curso básico gerencial de custos. São Paulo: Pioneira Thomson Learning. $377 \mathrm{p}$.

RICHARDSON, Roberto Jarry et al. (1999). Pesquisa social: métodos e técnicas. (3 ed.). São Paulo: Atlas.

SANTOS, Joel José dos. (2005). Fundamentos de custos para formação do preço e do lucro. (5 ed.). São Paulo: Atlas.

SLACK, Nigel. et al. (1997). Administração da produção. São Paulo: Atlas. 726 p.

VIANA, João José. (2000). Administração de materiais: um enfoque prático. São Paulo: Atlas. 448 p.

Data de Submissão: 02/08/2009

Data de Aceite: 19/03/2010 